\title{
Mathematical Modeling of pH-Based Potentiometric Biosensor Using Akbari-Ganji Method
}

\author{
R. Shanthi ${ }^{1}$, M. Chitra Devi ${ }^{2}$,Marwan Abukhaled ${ }^{3}$,Michael E.G. Lyons ${ }^{4}$, L. Rajendran ${ }^{1, *}$ \\ ${ }^{1}$ Department of Mathematics, AMET (Deemed to be University), Kanathur, Chennai, India \\ ${ }^{2}$ Department of Mathematics, Anna University, University College of Engineering, Dindigul, India. \\ ${ }^{3}$ Department of Mathematics and Statistics, American University of Sharjah, Sharjah, UAE \\ ${ }^{4}$ School of Chemistry \& AMBER National Centre, University of Dublin, Trinity College Dublin, \\ Dublin 2, Ireland \\ *E-mail: raj_sms@ rediffmail.com
}

Received: 8 December 2021 / Accepted: 22 January 2022 / Published: 2 February 2022

\begin{abstract}
This study discusses a mathematical model for the steady-state reaction of a $\mathrm{pH}$-based potentiometric biosensor immobilizing organophosphorus hydrolase $(\mathrm{OPH})$. The model that combines diffusion and enzymatic reaction processes in the membrane is a system of five interconnected nonlinear reactiondiffusion equations. Approximate analytical expressions for the substrate concentration (organophosphorus pesticides (OPs)) and products are derived for all possible values of Thiele modulus and buffer concentration using the Akbari-Ganji method. In addition, analytical expressions for the current, sensitivity, and resistance of $\mathrm{pH}$-based potentiometric biosensors are also derived. The obtained analytical results are convergent on the prescribed domain and firmly match the fourth-order RungeKutta numerical simulations.
\end{abstract}

Keywords: Mathematical modeling, reaction-diffusion, pH-based potentiometric biosensor, AkbariGanji method, nonlinear equations.

\section{FULL TEXT}

(C) 2022 The Authors. Published by ESG (www.electrochemsci.org). This article is an open access article distributed under the terms and conditions of the Creative Commons Attribution license (http://creativecommons.org/licenses/by/4.0/). 